\title{
Lunar phobia in the greater fishing bat Noctilio leporinus (Chiroptera: Noctilionidae)
}

\author{
Karrigan S. Börk ${ }^{1}$ \\ 1 Department of Biodiversity, Ecology, and Evolutionary Biology, University of Kansas, Lawrence, KS 66045, USA; \\ karrigan_bork@email.com
}

Received 21-XI-2002. C Corrected 29-I-2006. Accepted 09-VIII-2006.

\begin{abstract}
The nightly activity patterns of Noctilio leporinus, a piscivorous neotropical bat, were documented by visual observation over one lunar cycle at a large dock in Golfito, Costa Rica. The activity patterns were compared to the intensity of the moonlight, and a strong correlation between darkness and activity was observed ( $\mathrm{n}$ $=776, r^{2}=0.96$ ). This correlation has been observed in many species of mammals and may indicate adaptation by potential prey species to avoid predation by visually oriented nighttime predators and/or an adaptation by predators to maximize hunting success. Rev. Biol. Trop. 54 (4): 1117-1123. Epub 2006 Dec. 15.
\end{abstract}

Key Words: Noctilio, piscivore, lunar phobia, moonlight, predation, bat, foraging.

Avoidance of bright moonlight has been documented in small terrestrial mammals, including Allenby's gerbil, Gerbillus allenbyi (Kotler et al. 1991); bannertail kangaroo rat, Dipodomys spectabilis (Lockard and Owings 1974); greater Egyptian sand gerbil, Gerbillus pyramidum (Kotler et al. 1991); Merriam's kangaroo rat, Dipodomys merriami (Schwab 1966); in the southern flying squirrel, Glaucomys volans (Wildlife Rescue League, unpublished); and in a number of species of bats. Examples include one megachiropteran (Indian false vampire bat, Megaderma lyra (Subbaraj and Balasingh 1996)), andthree microchiropterans (Jamaican fruit-eating bat, Artibeus jamaicensis, (Morrison 1978)); pond bat, Myotis dasycneme (Voûte et al. 1974); and common vampire bat, Desmodus rotundus (Turner 1975). The broad occurrence of lunar phobia suggests strong selective pressures in nocturnal animals for moonlight avoidance. Safety from predators and availability of prey could both provide the necessary selective pressure.
Several studies indicate that reduced light impairs the hunting ability of visually oriented nocturnal predators (red fox, Vulpes vulpes, Kruuk 1964; Western Gull, Larus occidentali, Nelson 1989, Barn Owl, Tyto alba, Eagle Owl, Bubo bubo, Little Owl, Athene noctua, Kotler et al. 1991). Barred Owls (Strix varia) and Great Horned Owls (Bubo virginianis) both spent a significantly longer time hunting on dark nights, perhaps due to decreased predator effectiveness (O’Donnell 1999). Decreased predator effectiveness would encourage potential prey items to become more active in low light conditions. Bats may feed longer on dark nights due to decreased danger from predators.

Carnivorous bats such as Megaderma lyra or the greater fishing bat, Noctilio leporinus, could adopt a lunar phobic behavior in order to feed when they are more likely to detect and capture prey. Many marine organisms are more active in low light conditions, and thus prey availability may cause apparent lunar phobia, as has been suggested for petrels that 
feed on bioluminescent squid and other sea life (Imber 1975). This study investigates lunar phobia in N. leporinus and suggests several possible causes.

Noctilio leporinus is one of the few bats that depend on fish as a primary food source (Hood and Jones 1984). It possesses highly specialized body attributes for feeding extensively on fish, the most characteristic of which are highly modified feet with long, laterally flattened toes and sharply curved claws for gaffing fish (Fish 1991). Other attributes include its large size (50 - 90 g (Brooke 1994), body length 98 - $132 \mathrm{~mm}$ (Nowack 1999)) and wingspan (forearm length $>75 \mathrm{~mm}$, wingspan $500 \mathrm{~mm}$ ) (Hood and Jones 1984). The fishing bat's large wings allow it to drag its feet through the water over long distances and lift heavy prey free of the surface, and are coated with reflective water-shedding oil (Malino 1994). The combination of large wing size, large body, unique feeding behavior, and reflective wings generally permits differentiation of $N$. leporinus from the only similar congeneric species, Noctilio albiventris (Nowak 1994). N. albiventris does occasionally pursue insects in the water, but it has not been reported to have taken fish in the wild (LewisOritt et al. 2001).

Female Noctilio leporinus congregate at day roosts in harem groups of one male and 310 females. Bachelor males roost individually or in small groups. Day roosts include caves, hollow trees, and abandoned buildings. Harem females usually forage as a group, although males forage independently with no regard to their daytime associations (Brooke 1997). Night roosts are occupied only when the bats are between hunting bouts, and are used as a perch while chewing and swallowing food and for rest between feeding forays.

Noctilio leporinus uses two basic feeding styles, search flight and trawling (Altringham 1998). Search flight involves extended flights at varying heights above the water with echolocation calls to detect both the ripples made by fish and the fins which extend above the water when the fish breach. After locating a fish, the bat makes pointed dips in flight to gaff the fish on its claws. Trawling, or raking, consists of long drags of the claws through the water to capture fish. The bats trawl both at random and through areas of past productivity (Schnitzler et al. 1994). Fishing bats average one catch every 50-200 passes (Schnitzler et al. 1994).

\section{MATERIALS AND METHODS}

Golfito $\left(8^{\circ} 40^{\prime} \mathrm{N}, 84^{\circ} 5^{\prime} \mathrm{W}\right)$ is a small city in a bay off Golfo Dulce, Puntarenas Province, Costa Rica The temperature averages $27.5^{\circ} \mathrm{C}$ with little seasonal change, although the majority of the $4000-5000 \mathrm{~mm}$ of rain/year falls between March and December. The heavy rainfall supports tall, multistratal, lowland tropical rain forests (Cortés 1990). Much of the land in the immediate vicinity of Golfito is still primary growth, although there are patches of secondary growth in old cocoa plantations.

The study was conducted on a large industrial dock, $200 \mathrm{~m}$ long by $50 \mathrm{~m}$ wide and 5-10 $\mathrm{m}$ high. The dock overlooks the saltwater bay surrounded by the city of Golfito. The working dock has lights lit through the night that attract fish to the water below. The phenomenon of fish attraction to lights over the water is well documented (Verheijen 1958). The understructure of the dock is dark and is seldom disturbed by human activity. It affords numerous night roost opportunities for bats but does not appear to be used as a daytime roost.

Following the method of Watanuki (1986), a rectangular prism with imagined dimensions $10 \mathrm{~m}$ wide by $20 \mathrm{~m}$ tall by $40 \mathrm{~m}$ long was oriented with the short end toward the open ocean from a fixed position on the dock. This was designated the activity zone, and each bat passing through the zone was counted as an activity incident. Bats passing through multiple times indicated heightened activity in the area and were counted as multiple activity incidents. However, some bats circled repeatedly in and out of the activity zone in a short time period $(<10 \mathrm{~s})$, and these bats were counted only once, as in the Watanuki study (1986), in order to avoid artificially high 
activity numbers created solely by the location of the bat activity on the edge of the activity zone. Activity incidents were tallied in $15 \mathrm{~min}$ activity periods.

Bats were detected with a Belfry Bat Detector (Convergence Technologies, Pleasantville, New York, USA), and N. leporinus was identified on the fly by its distinctive features and behaviors. Identification was confirmed with a mist net capture. The device detected bats up to $40 \mathrm{~m}$ away, but only those bats identified as fishing bats were counted as activity incidents.

Moonlight intensity was ranked at the beginning of each activity period according to the following scale:

5 - Full moon, no clouds

4 - Full moon light clouds, gibbous moon

3 - Quarter moon, obscured full moon

2 - Obscured gibbous moon, quarter moon and light clouds, very obscured full moon

1 - Very little ambient light

0 - No light, new moon

The numerical rankings allow for statistical comparison of light levels and bat activity. Rain may affect bat activity, so activity periods with rainfall were discarded to allow a direct examination of the relationship between moonlight levels and fishing bat activity. Using the model from Morrison's (1978) experiment on lunar phobia in A. jamaicensis, data also were grouped based on the light and dark half of the lunar cycle.

Data groups were subjected to an f-test for sameness of variance between the light and dark cycles, and a t-test for sameness of mean activity incidents in the light and dark cycle. Within the daily data, mean activity incidents per activity period for each level of light intensity were computed and tested for correlation between moonlight indices and activity levels.

Data were collected from 5:00 PM to 5:00 $\mathrm{AM}$, three nights per week, for the duration of one lunar cycle. Observation began on 13 June 2000 and continued through the night of 6 July 2000. First quarter moon was 9 June 2000, full moon was 16 June 2000, last quarter was 25 June 2000, and new moon was 1 July 2000.

\section{RESULTS}

A total of 776 activity incidents were observed in dry conditions.

Foraging behavior: Noctilio leporinus generally arrived at the study site around 5:00 PM, 45 min after sundown. In the absence of moonlight and rain, the activity continued for up to four hours and then declined. The morning hours occasionally brought an additional feeding period, between 1:30 AM and 3:30 $\mathrm{AM}$, although the second feeding period also varied according to environmental factors. On nights when the usual feeding period was very bright or rainy, the bulk of feeding activity shifted to a later time. Bats generally fed in a manner well documented in other population studies (Brooke 1997). They often were seen flying in groups of up to six bats, and would fly in a line, with 5-7 $\mathrm{m}$ between each bat, following the lead bats flight patterns. These bats, presumably females (Brooke 1997), would dip in the same areas as the lead bat, and followed the lead bat's side-to-side flight path as well. Other bats, presumably male (Brooke 1997), fed independently but appeared to home in on other bats' activity to locate concentrations of fish.

Individual bats employed high and low search flights to detect small fish, and made pointed dips in the areas of fish activity, but they did not exhibit the long rakes or trawls that are considered characteristic (Schnitzler et al. 1994). All contacts with the water were snatches that lasted $<0.5$ s. Additionally, the bats often waited under the dock and flew out to investigate splashes in the water, although they did not leave the night roosts for large flying insects passing under the lights.

The bats concentrated their feeding in areas well lit by dock lights or by lights from large boats in the area. These areas were generally close to centers of human activity, but the bats were apparently not influenced by these 
disturbances. The well-lit areas appeared to have the highest concentration of surface disturbances from fish activity, and the bats tended to cruise from one lit area to another to find active fish. When the bats detected fish in one area, they tended to concentrate their efforts in that area until the fish activity declined.

Predators: Several large birds of prey were seen in the area, but the species could not be determined because of the low light conditions. Possibilities may include several gulls (Laridae) or typical owls (Strigidae) (Stiles and Skutch 1989). The Black and White Owl is known to take fishing bats (Stiles and Skutch 1989). The guards on the dock reported seeing numerous "Buhos", a generic term for an owl that suggests the latter possibility, although numerous gulls of unknown species were present in the area in the late evenings. The guards also reported a decline in the number of bats at the dock over the last five years, beginning after they began seeing owls in the area.

One attempted capture of a bat by a large fish of unidentified species was observed, but it appeared to be an isolated incident. No other predators on Noctilio leporinus were noted in the area.

Lunar phobia: Noctilio leporinus demonstrated strong lunar phobia. The bats are significantly more active in low light conditions than when the moon shines brightly (Fig. 1), based on activity period comparisons. On a lunar cycle basis, the same number of bats was active during the light and dark cycles $(\mathrm{n}=376$ for light cycle, 391 for dark cycle). However, the variance was much higher in the light cycle (light s ${ }^{2}$ $=15.50$, dark $\left.\mathrm{s}^{2}=8.727, \mathrm{p}<0.01\right)$. These findings suggest that the bats had the same overall level of activity during the light and dark cycles, although the activity during the light cycle was clumped in the darker activity periods and the activity during the dark cycle was more evenly distributed throughout the night, which supports the hypothesis that the bats are more active in periods of low light (Fig. 2, 3).

Although the dock lights were on throughout the experiment, the bats showed no fear

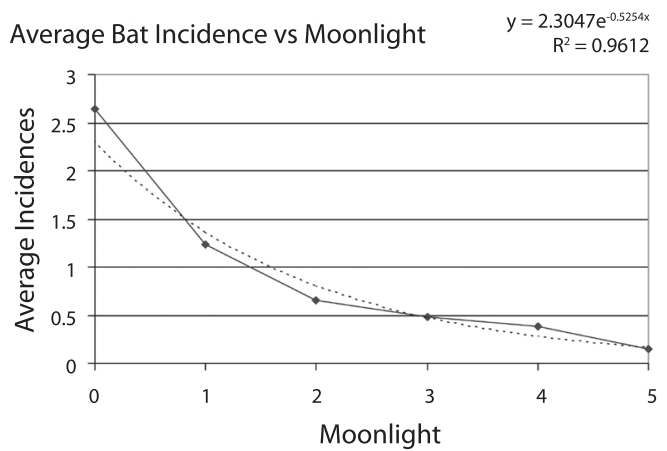

Fig. 1. Average activity level by ambient moonlight (1 is darkest, 5 is brightest) for the greater fishing bat $N$. leporinus.

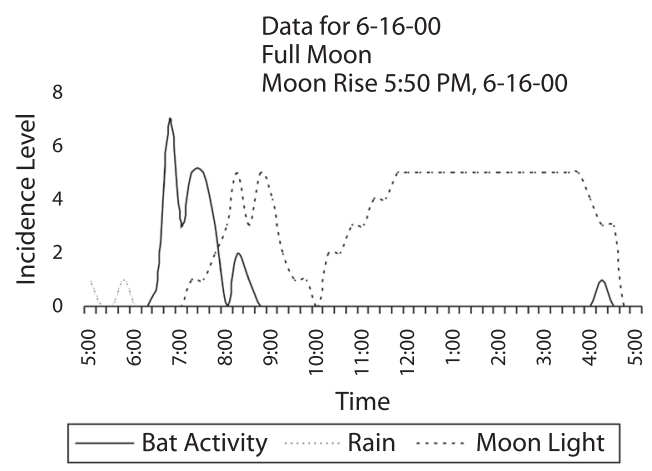

Fig. 2. Average greater fishing bat ( $N$. leporinus) activity level, rain and moon light by time for June 16, 2000, a full-moon night.

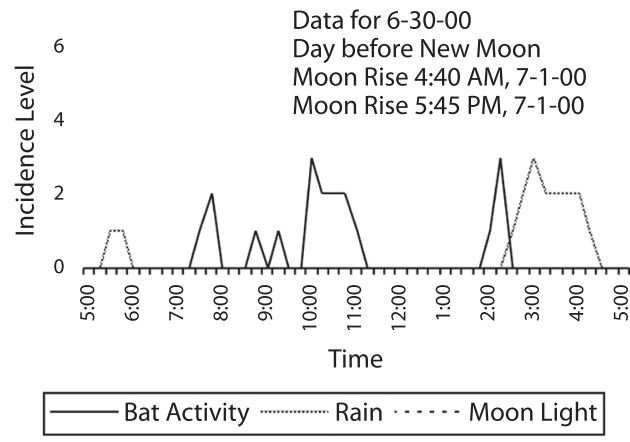

Fig. 3. Average greater fishing bat ( $N$. leporinus) activity level, rain and moon light by time for June 16, 2000, a new-moon night. Moonrise occurred after sunrise, so no moonlit periods are reflected in the data.

of the light from these sources and fed in and around the light, not in the dark areas away from the dock. This pattern mirrored 
the apparent activity patterns of the small fish eaten by the bats.

Foraging behavior: Although Noctilio leporinus is generally classified as a piscivore, its diet in Culebra, Puerto Rico during the wet season was dominated by moths, beetles, and other insects (Brooke 1994). Another study, carried out in Tortuguero, Costa Rica, noted only two insect captures in hundreds of hours of foraging study and stated that $N$. leporinus would not deviate from its course to pursue insects that would invite a chase in insectivorous bats (Schnitzler et al. 1994). In this study, $N$. leporinus was not seen chasing or feeding on insects. Bats did not respond to large insects in flight near the night roosts, only to splashes in the water, reinforcing the view of $N$. leporinus as a piscivore and further suggesting reliance on hearing as opposed to vision for long-range prey detection. The night perch was in an area frequented by large beetles, cockroaches, crickets, and crabs, all items noted as significant to the bats' diet in Puerto Rico (Brooke 1994). The bats might depend more on this resource when they cannot spend as much time hunting due to rain. $N$. leporinus appears to concentrate on fish as its primary food source while feeding opportunistically on other organisms.

The bats in this study did not perform the long trawls described by Schnitzler et al. (1994). The water surrounding the dock generally had mild chop throughout the night, which may make the long rake significantly less effective, accounting for its absence in this population.

Lunar phobia: Many nocturnal creatures correlate their behavior to moonlight intensity. Based on the data presented in this study, Noctilio leporinus follows this trend by becoming more active in low light situations.

Previous study of lunar phobia in bats has concentrated on the relation of bat activity levels to the lunar cycle (Morrison 1978, Subbaraj and Balasingh 1986). The existence of an internal lunar clock in several bat species has been hypothesized, but this hypothesis fails for Noctilio leporinus because the bats were just as active in the light cycle as in the dark cycle, although the activity was grouped differently in each period (Fig. 2 and 3). This variation results from the uniform darkness of the dark cycle nights, which permitted activity throughout the night, and the irregular darkness of the light cycle, which permitted only "clumps" of activity in the intermittent dark periods. The lunar cycle appears to play no role in the overall activity level of $N$. leporinus, consistent with Haussler and Erkert's study (1978) showing that activity patterns in Neotropical bats change with exposure to light, not moon cycles.

The owl predation studies (Kotler 1991, O'Donnell 1999) suggest that owls are more successful in well-lit conditions. If bats learn that brighter moonlight brings increased predator activity, or if those bats that fail to associate bright light with predator activity are more likely to be eaten, the bats will eventually exhibit lunar phobia. This lunar phobia contrasts with the apparent preference for artificially lit areas for feeding, although this preference seems likely to be a result of prey behavior.

Lunar phobia in $N$. leporinus may be a response to the activity patterns of prey items. A similar observation was made in $M$. lyra (Subbaraj and Balasingh 1996), but this influence in that study was dismissed without discussion. $N$. leporinus does ignore its lunar phobic tendencies when prey items present themselves in the bats' immediate area. Dark periods increase the contrast between the surface areas lit by artificial sources and non-lit areas, concentrating fish in lit areas during darker cycles (Verheijen 1958, Pet et al. 1997, Parrish 1999). A higher concentration of fish increases the chance of a bat catching a fish, which could encourage the bat to concentrate its activity spatially in lit areas and temporally during dark periods. The light periods results in decreased contrast and may result in a dispersion of the fish, encouraging the bats to wait for more productive hunting periods. A similar phenomena is found in light fisheries, with human fishing efforts concentrated in the low light periods of the lunar cycle (van 
Oostenbrugge 2002) The higher concentration of fish activity in lit areas would also account for the bats' apparent fearlessness under the dock lights. Prey activity was not measured in this study, and this hypothesis merits further exploration. This possibility would also suggest that the lunar phobia in this population might be a result of human disturbance; a similar study on a more isolated bat population would clarify the origin of this behavior.

Prey availability seems to account for the bats' occasional flights in bright moonlight. Bats seldom left their night roosts in periods of high moonlight levels, except when induced to do so by large amounts of activity at the water's surface. This response may be a result of hunger or of a need to capitalize on a feeding opportunity, not sudden reduction in lunar phobia. The bats in this study made at least one attempt to feed every night, regardless of overall light conditions. A similar explanation was suggested for periods of apparent disregard for moonlight in other lunar phobic bats (Morrison 1978, Subbaraj and Balasingh 1996). When an easy feeding opportunity presents itself, the benefits outweigh the risks involved in exposure to the moonlight, and the bats will feed, even on well-lit nights. These results suggest that lunar phobia in Noctilio leporinus is likely a function of predator avoidance and prey availability.

\section{ACKNOWLEDGMENTS}

I thank Barbara Schowen and the Honors Program at the University of Kansas for providing funding for this project. I appreciate the guidance and instruction I received from Gloriana Chaverri. I am indebted to Laura Bork and José Cordero for dockside support. Finally, I thank Thor Holmes and Robert Timm for their reviews.

\section{RESUMEN}

Documenté los patrones de actividad nocturna de Noctilio leporinus, murciélago piscívoro neotropical, mediante observaciones visuales durante un ciclo lunar en un muelle de Golfito, Costa Rica. Considerando la intensidad de la luz lunar, hubo una fuerte correlación entre la oscuridad y la actividad $\left(\mathrm{n}=776, \mathrm{r}^{2}=0.96\right)$. Esta correlación ha sido observada en muchas especies de mamíferos y puede indicar una adaptación de presas potenciales para evadir los depredadores nocturnos y/o una adaptación de los depredadores para maximizar el éxito de cacería.

Palabras clave: Noctilio, piscívoro, fobia lunar, luz de luna, depredación, murciélago, búsqueda de alimento.

\section{REFERENCES}

Altringham, J.D. 1998. Bats: Biology and Behavior. Oxford University, London, England. 272 p.

Brooke, A.P. 1994. Diet of the fishing bat, Noctilio leporinus (Chiroptera: Noctilionidae). J. Mammal. 75: 212-218.

Brooke, A.P. 1997. Social organization and foraging behavior of the fishing bat, Noctilio leporinus (Chiroptera: Noctilionidae). Ethology 103: 421-436.

Cortés, J. 1990. Coral reef decline in Golfo Dulce, Costa Rica, eastern Pacific: anthropogenic and natural disturbances. Ph.D. Dissertation. University of Miami, Miami, Florida, USA. 147 p.

Fish, F.E., B.R. Blood \& B.D. Clark. 1991. Hydrodynamics of the feet of the fish-catching bats: Influence of the water surface on drag and morphological design. J. Exp. Zool. 258: 164-173.

Haussler, U. \& H. Erkert. 1978. Different direct effects of light intensity on the entrained activity rhythm in Neotropical bats. Behav. Process. 3: 223-239.

Hood, C.S. \& J.K. Jones Jr. 1984. Noctilio leporinus. Mamm. Species 216: 1-7.

Imber, M. J. 1975. Behaviour of petrels in relation to the moon and artificial lights. Notornis 22: 302-306.

Kotler, B.P., J.S. Brown \& O. Hasson. 1991. Factors affecting gerbil foraging behavior and rates of owl predation. Ecology 72: 2 249-2 260.

Kruuk, H. 1964. Predators and anti-predator behavior of the Black-headed Gull (Larus ridibundis L.). Behav. Suppl. XI.

Lewis-Oritt, N., R. Van Den Bussche \& R. Baker. 2001. Molecular evidence for piscivory in Noctilio (Chiroptera: Noctilionidae). J. Mamm. 82: 749-759.

Lockard, R.B. \& D.H. Owins. 1974. Moon-related surface activity of bannertail (Dipodomys spectabilis) and Fresno (D. nitratoides) kangaroo rats. Anim. Behav. 22: 262-273. 
Malino, E. 1994. Costa Rican adventure. Bats 12: 16-17.

Morrison, D. 1978. Lunar phobia in a Neotropical fruit bat, Artibeus jamaicensis (Chiroptera: Phyllostomidae). Anim. Behav. 26: 852-855.

Nelson, D.A. 1989. Gull predation on Cassin's Auklet with the lunar cycle. Auk 106: 495-497.

Nowack, R. 1994. Walker's Bats of the World. John Hopkins University, Baltimore,Maryland, USA. 296 p.

Nowack, R. 1999. Bulldog Bats, or Fisherman Bats. Walker's Mammals of the World. John Hopkins University, Baltimore, Maryland, USA. 347-349.

O’Donnell, R.P. 1999. The effects of moon phase and moonlight intensity on the activity of Barred Owls and Great Horned Owls. Poster, Meeting of the Northeast Regional Animal Behavior Society.

Parrish, J.K. 1999. Using behavior and ecology to exploit schooling fishes. Environ. Biol. Fish. 55: 89-103.

Pet, J.S., W.L. T van Densen, M.A.M. Machiels, M. Sukkel, D. Setyohadi \& A. Tumuljadi 1997. Catch, effort, and sampling strategies in the highly variable sardine fisheries around East Java, Indonesia. Fish Res. 31: 121-137.

Schnitzler, H.U., E.KV. Kalko, I. Kaipf \& A.D. Grinnell. 1994. Fishing and echolocation behavior of the greater bulldog bat, Noctilio leporinus, in the field. Behav. Ecol. Sociobiol. 35: 327-345.

Stiles, G.F. \& A.F. Skutch. 1989. A Guide to the Birds of Costa Rica. Comstock. Ithaca, New York, New York, USA. 656 p.

Subbaraj, R. \& J. Balasingh. 1986. Night roosting and 'lunar phobia' in Indian false vampire bat Megaderma Lyra. J. Bombay Nat. Hist. Soc. 93: 1-7.

Turner, D.C. 1975. The Vampire Bat: A Field Study in behavior and ecology. John Hopkins University, Baltimore, Maryland, USA. 159 p.

Van Oostenbrugge, J.A.E., J.J. Poos, W.L.T. van Densen \& M.A.M. Machiels. 2002. In search of a better unit of effort in the coastal liftnet fishery with lights for small pelagics in Indonesia. Fisheries Res. 59: 43-56.

Verheijen, F.J. 1958. The mechanisms of the trapping effect of artificial light sources upon animals. Ext. Arch.s Neerl. Zool. 13: 1-107.

Voûte, A.M., J.W. Sluiter \& M.P. Grimm. 1974. The influence of the natural light-dark cycle on the activity rhythm of pond bats (Myotis dasycneme Boie, 1825) during summer. Oecologia (Berlin) 17: 221-243.

Watanuki, Y. 1986. Moonlight avoidance behavior in Leach's Storm-Petrels as a defense against Slatybacked Gulls. Auk 103: 14-22. 
